We feel that awareness of economical issues in the Health Service provisions as well as further research with more refined tools of assessment would enhance the development of responsive services for this population.

Division of Psychiatry

Guy's Hospital, London SE1 9RT

Reference

Bouras, N. \& Drummond, C. (1989) Community psychiatric service in mental handicap. Health Trends, 21, 72.

\section{Importance of basic sciences to education in psychiatry}

DeAR SIRS

I read the article by Professor Crisp (Psychiatric Bulletin, March 1990, 14, 163-164) with great interest.

I agree with the importance of understanding basic research methodology and training at registrar level. I would also like to draw attention to the importance of continuing education and training in the basic sciences as relevant to psychiatry.

Having to organise the North West Thames Regional Health Authority Senior Registrar PostGraduate training scheme in the psychiatry of mental handicap, I had to review the basic specialists' training programme in psychiatry, and also evaluate the present senior registrars' training needs, together with general research interests and publication trends in the psychiatry of mental handicap.

I screened all subjects and headlines on mental retardation in the Cumulative Index Medicus for the year 1988, and also six outstanding clinical journals of mental handicap for the year 1988.

Comparing the total number of papers on mental retardation in Cumulative Index Medicus $(\mathrm{n}=1575)$ to the numbers of papers in six journals of mental handicap $(n=210)$, showed that only $13.5 \%$ of all the papers on the subject were published in the journals of mental retardation. Of all the papers, $86.5 \%$ were published in journals of general psychiatry, medicine, neurology, genetics and in the whole range of basic behavioural sciences publications as covered by Cumulative Index Medicus.

This is a proof of both the wealth of information on the subject of mental handicap and also the contribution of those clinical subjects and sometimes scientific dilemmas to all basic sciences and other disciplines.

It is also a proof of the clinician's need to understand and follow basic scientific progress and its importance in applying new diagnostic and treatment methods and designing sophisticated research programmes.

Both basic specialist and post-graduate training in all sections of psychiatry should underline the importance of basic sciences as well as teaching and research experience.

Charing Cross and

D. KOHEN

Westminster Medical School

Unit of Mental Handicap

24 St Dunstans Road,

London W6 8RP

\section{Section 37-Mental Health Act}

\section{DEAR SIRS}

There is a curious provision in the Mental Health Act 1983 for the discharge of patients admitted under S.37 of the Act. Schedule I Part I of the Act modifies the applicability of the powers of discharge under S.23(2)a of the Act so that the nearest relative does not have the power of discharge, but the powers of the hospital managers to discharge the patient are retained. Indeed the Mental Health Act Leaflet 8 ("Your rights under the Mental Health Act 1983") which is handed to patients admitted under S.37 states:

"If you think you should be allowed to leave hospital you should talk to your doctor. If he thinks you should stay, but you still want to leave, you can ask the hospital managers to let you go. You should write to them to ask them to do this".

It is surprising that the hospital managers should have powers which can override the decision of even a High Court judge, who makes a Hospital Order after considering "all the circumstances including the nature of the offence and the character and antecedents of the offender ..." (S.37(2)b), before deciding that a Hospital Order is the most appropriate disposal. Many colleagues, including Mental Health Act Commissioners, seem unaware of this provision, and it would be interesting to know what the effects are in practice. So far, none of my own patients have been discharged in this way, but I know of one case where a S.37 patient was discharged by the managers against the advice of the Responsible Medical Officer (although their decision proved invalid for technical reasons). One fears that if the courts become aware that their decisions can be overruled by hospital managers against medical advice, they may be less ready to accept medical recommendations for a Hospital Order.

The Royal Free Hospital

P. T. D'ORBAN 